\title{
LA NARANJA ATÓMICA: ESCRIBIR PARA DIVULGAR
}

\author{
Y.Hernández,S.Higuera \\ Grupo de Física Teórica y Computacional
}

\section{RESUMEN}

Este artículo da cuenta dinámica y los resultados de un trabajo divulgativo, cuyo propósito se ha centrado en la utilización de la radio como una herramienta para difundir ciencia; en este sentido se considera como un instrumento de constante aprendizaje para los radioescuchas interesados, así como un elemento para hacer accesible el conocimiento científico a una población muy diversa. Igualmente, se presentan una serie de resultados acerca del grado de interacción que este método de difusión de la física ha tenido en la comunidad boyacense.

Palabras claves: divulgación científica, radio, enseñanza de la física.

\section{Introducción}

Gran parte del desarrollo tecnológico ha sido impulsado por las ciencias básicas, especialmente la física ha estado ligada a la evolución y la comprensión del universo; pero ¿cómo transmitir al parecer, el abstracto y oscuro mundo de la física? y ¿cómo traducir el lenguaje científico, para quienes no tienen una conexión directa con el estudio profundo de las leyes que rigen la naturaleza? Sabemos que nunca la ciencia ha estado tan presente como ahora en nuestra vida cotidiana y a la vez nunca ha estado más alejada del conocimiento público, esto nos permite establecer un corte radical entre los científicos y el resto de la población, por ésta razón, desde hace siete años la física tiene un espacio de divulgación con el programa radial denominado "La Naranja Atómica", mediante el cual ésta ciencia se hace presente en la población boyacense, el programa ha sido impulsado por estudiantes de pregrado en física de la Universidad Pedagógica y Tecnológica de Colombia. Así, nos unimos con el propósito de informar, divertir, convencer, contar, describir ciencia y ante todo pura física. De ésta forma, se manifiesta una interacción directa con la comunidad, brindando un espacio de tertulia para los filósofos de la naturaleza. Queremos cambiar el paradigma de la física y asumimos con éste programa un nuevo reto: "el de escribir para divulgar"; reto que legamos a las siguientes generaciones de estudiantes de Física. 


\section{Trayectoria de "La Naranja Atómica"}

Hacia el año 2001, nace la iniciativa de formar un programa radial especializado en física, basados en la idea de: "la radio como medio masivo de fácil acceso al público y como nueva alternativa para explicar la ciencia", cuya idea se cristalizó con la oportunidad que brindaba la emisora de la Universidad Pedagógica y Tecnológica de Colombia, de ofrecer un espacio a la escuela de física para intentar llegar a la comunidad boyacense. Atendiendo a éste llamado se ideó el proyecto "La Naranja Atómica", donde un grupo de tres estudiantes de física integraron la que sería la primera generación del programa, quienes contaron con una preparación adecuada por medio de talleres, redacción de libretos y expresión oral. La naranja atómica salió al aire en Agosto de 2001 a las 7:30 p.m.

Transcurridos dos años de intensa labor, surge la segunda generación con estudiantes de cuarto y quinto semestre de física, logrando una mayor interacción con los constructores de la ciencia a nivel nacional e internacional, "resaltando una entrevista al fallecido profesor Marcelo Alonso". La tercera generación, conformada por cuatro estudiantes de últimos semestres, aportó secciones con el fin de darle una dinámica estructurada al desarrollo del programa, entre éstas secciones se cuentan: "Historias y Avances de la Ciencia", "Curiosidades de la Ciencia", "Somos pura y Física, Física" y "Pregunta Daniel". Actualmente, con la nueva generación se ha creado una sección denominada "'La feria ambulante de la Ciencia", la cual busca el contacto directo entre el público y la divulgación científica, además se ha tenido la oportunidad de interactuar con los artífices de la ciencia en seminarios, eventos y coloquios planeados en nuestra escuela y el objetivo primordial ha sido el de escribir para divulgar. Hoy han sido siete años de ésta labor en los que cuatro generaciones de estudiantes de física han transmitido el legado de la divulgación científica. Por último, cabe resaltar la presencia de La Naranja Atómica en importantes eventos como el Congreso Nacional de Física y el Congreso Nacional de la Enseñanza de la Física.

\section{Propuesta}

Hacia el siglo XIX un matemático, Gorgonne, afirmaba: "Nadie puede enorgullecerse de haber dicho la última palabra sobre una teoría, en tanto no la pueda explicar en términos sencillos a cualquiera que encuentre en la calle". La manifestación de la ciencia y, especialmente, de la física a la sociedad presenta una serie de problemas debido a diversas causas; entre estas causas se exhibe la gran complejidad de esta disciplina científica y la dificultad de una correcta decodificación del lenguaje científico al habla cotidiana. Así, la comunidad en general busca un medio que los haga participes del conocimiento científico, de sus beneficios y de sus riesgos, con el fin de poder resolver sus interrogantes, $y$ 
de 'esta manera lograr que la ciencia sea un espacio más de su vida diaria. Por esta razón, una de las principales características que la Naranja Atómica tiene en cuenta es saber escribir para divulgar, es decir, mostrar a una comunidad en un contexto no tan especializado sino mas bien cotidiano, avances, conceptos $y$ explicación de fenómenos que a veces nos alejan del maravilloso mundo de la física (claro está, manteniéndonos dentro de la correcta divulgación del conocimiento cientifico). Este ha sido uno de nuestros grandes retos, sabemos que la ciencia y la tecnología influyen sobre nosotros y queremos expresar cómo la física está presente también en el desarrollo integral y exitoso de los avances, que permiten al ser humano ir de la mano con la vertiginosa evolución del mundo. "Hoy se abre paso en el mundo la convicción de que en una sociedad cada vez más dependiente del conocimiento tecnológico es muy importante contar con una información honrada, critica y exhaustiva sobre ciencia y tecnología. Ello obliga a replantear las relaciones entre ciencia e información a las que debe añadirse la educación. Como es bien conocido los textos científicos presentan una estructura diferente. El manejo del lenguaje cambia según varían sus intenciones de transmitir. Primordialmente éstos pretenden informar a través de argumentación y usando un lenguaje preciso. Dadas las razones anteriores para cumplir nuestro objetivo, con La Naranja Atómica pretendemos: Transmitir pensamientos y avances de ła ciencia, Crear lazos que nos permitan interactuar con la sociedad especialmente, con la comunidad Boyacense, y Hacer de la ciencia un juego comunicativo que nos permita superar las barreras espacio-temporales de información.

\section{Resultados}

En la tabla 1, se presenta un estudio realizado para el año 2006, en la que se muestra el puesto ocupado por la Emisora de la UPTC en la ciudad de Tunja, dentro de 30 Emisoras Públicas e Independientes para el nivel de audiencia categorizado a un margen de edades.

\begin{tabular}{|l|l|l|l|l|}
\hline ANO & PUESTO & $12-19$ & $20-24$ & $25-34$ \\
\hline 2000 & 10 & 200 & 500 & 800 \\
\hline
\end{tabular}

Tabla 1: Estudio del nivel de sintonía, por edades

En la tabla 2, se presenta los resultados de un estudio de medios en el que se muestra el nivel de audiencia de las Emisoras independientes en la ciudad de Tunja, en la franja de $2 \mathrm{pm}$ a $5 \mathrm{pm}$, periodo en el cual La Naranja Atómica Emite su programa Radial. 


\begin{tabular}{|l|l|}
\hline EMISORA & AUDIENCIA \\
\hline UPTC TUNJA & 523 \\
\hline COLBOY STEREO & 466 \\
\hline ARMONIA UNIVERSAL & 393 \\
\hline VIDA & 215 \\
\hline LANCEROS STEREO & 185 \\
\hline ARMONIA BOYACENSE & 184 \\
\hline ICBA STEREO & 142 \\
\hline
\end{tabular}

Tabla 2: Estudio del nivel de sintonía, comparado con otras emisoras regionales

En la siguiente tabla, se presenta un estudio realizado para el año 2006, en la que se muestra el puesto ocupado por la Emisora de la UPTC en la ciudad de Tunja, dentro de 30 Emisoras Públicas e Independientes para el nivel de audiencia categorizado por género.

\begin{tabular}{|l|l|l|l|}
\hline AÑO & PUESTO & HOMBRES & MUJERES \\
\hline 2006 & 10 & 1300 & 1400 \\
\hline
\end{tabular}

Tabla 3: Estudio del nivel de sintonía, por género

\section{Referencias}

[1] Calvo,M. Estrategias para Divulgar el Conocimiento, Asociación Española de Periodismo Científico.

[2] Bueno, W. Os novos desafíos do jornalismo científico, edición mimeografiada.

[3] Marques de Melo,]. Teoria da divulgacao científica, Universidad de S. Paulo. Escola de Comunicacoes e Artes. Núcleo José Reis de Divulgacao Científica. S. Paulo, 1992.

[4] Chaparro,M. De la Ciencia al Pueblo por la vía Periodística, en Arbor junio julio: 4358,1990 . 